\title{
Basal Nucleotide Levels, Release, and Metabolism in Normal and Cystic Fibrosis Airways
}

\author{
Scott H. Donaldson, Eduardo R. Lazarowski, Maryse Picher, \\ Michael R. Knowles, M. Jackson Stutts, and Richard C. Boucher \\ Cystic Fibrosis Research and Treatment Center, University of North Carolina, \\ Chapel Hill, North Carolina, U.S.A.
}

Accepted July 18, 2000.

\begin{abstract}
Background: Cystic fibrosis (CF) is a syndrome caused by mutations in the cystic fibrosis transmembrane regulator (CFTR) gene. Despite advances in our understanding of the molecular pathogenesis of $C F$, the link between CFTR gene mutations and the pathogenesis of CF lung disease remains poorly defined. CFTR has been assigned a number of putative functions that may contribute to innate airway defense, including the regulation of adenosine 5 '-triphosphate (ATP) release into the extracellular environment. Because extracellular ATP and uridine 5' -triphosphate (UTP) may regulate airway mucociliary clearance via interaction with luminal $\mathrm{P}_{2} \mathrm{Y}_{2}$ receptors, the loss of CFTR-mediated nucleotide release could explain the defect in CF airway defense.

Materials and Methods: We tested the physiologic importance of CFTR-mediated nucleotide release in vivo by directly measuring levels of ATP and UTP in nasal airway surface liquid from normal and CF subjects. Because these basal nucleotide levels reflect the net activities of nucleotide release and metabolic pathways, we also measured constitutive rates of nucleotide release and metabolism on well-differentiated
\end{abstract}

normal and CF airway cultures in vitro. The measurement of ATP release rates were paralleled by in vivo studies employing continuous nasal perfusion in normal and CF subjects. Finally, the regulation of ATP release by isoproterenol and methacholinestimulated submucosal gland secretion was tested.

Results: These studies revealed that steady-state ATP and UTP levels were similar in normal (470 \pm $131 \mathrm{nM}$ and $37 \pm 7 \mathrm{nM}$, respectively) and CF (911 \pm $199 \mathrm{nM}$ and $33 \pm 12 \mathrm{nM}$, respectively) subjects. The rates of both ATP release and metabolism were also similar in normal and CF airway epithelia both in vitro and in vivo. Airway submucosal glands did not secrete nucleotides, but rather, secreted a soluble nucleotidase in response to cholinergic stimuli.

Conclusion: The concentration of ATP in airway surface liquid is in a range that is relevant for the activation of airway nucleotide receptors. However, despite this finding that suggests endogenous nucleotides may be important for the regulation of mucociliary clearance, our data do not support a role for CFTR in regulating extracellular nucleotide concentrations on airway surfaces.

\section{Introduction}

Cystic fibrosis (CF) is a monogenetic disease characterized by chronic airway infection and bronchiectasis that is caused by mutations in the cystic fibrosis transmembrane regulator (CFTR) gene. It is clear that CF patients have impaired

Address correspondence and reprint requests to: Scott H. Donaldson, M.D., 7017 Thurston Bowles Bldg., CB \#7248, CF Research and Treatment Center, University of North Carolina, Chapel Hill, NC 27599, U.S.A. Phone: 919-966-7046; Fax: 919-966-7524;

Email: tauras@med.unc.edu lung defense, but the relationship between CFTR function and protection from progressive airway infection and inflammation is uncertain. Although CFTR functions as a cAMP-regulated chloride channel $(1,2)$, this property may not account for the spectrum of abnormalities observed in CF airway epithelia. A second function for CFTR, as a regulator of other ion channels, has more recently been described. For example, the loss of inhibitory effects on the epithelial sodium channel due to absent or mutated CFTR leads to sodium hyperabsorption 
$(3,4)$, which may contribute to CF airway disease pathogenesis $(5,6)$. A third function proposed for CFTR is as an ATP channel and/or regulator of ATP release (7-14). Since ATP can regulate mucociliary clearance via airway $\mathrm{P}_{2} \mathrm{Y}_{2}$ nucleotide receptors $(15,16)$ by increasing cilia beat frequency (17-19), chloride secretion $(20,21)$, and goblet cell degranulation $(22,23)$, mutations in CFTR could lead to a reduced ATP concentration on airway surfaces and adversely affect lung defense.

The earliest notion that CFTR may be involved in ATP transport emanated from studies of the multi-drug resistance protein (MDR), which like CFTR, is a member of the ATPbinding cassette $(\mathrm{ABC})$ family of transporters (24). Subsequently, a number of in vitro studies showed either direct ATP conduction through CFTR using patch clamp techniques, or evidence for a direct relationship between normal CFTR expression and ATP release (7-14). Conflicting with these reports, however, are studies using a variety of methodologies that could not detect CFTR-dependent ATP release (25-29). It may be difficult to resolve these discrepant results, because of the wide variety of heterologous cells and techniques employed. As an alternative approach, we utilized an in vivo approach to investigate the relevance of CFTRmediated nucleotide release from airway epithelial cells.

Using the nose as an in vivo model of human airways, we measured basal concentrations of ATP and UTP in nasal airway surface liquid (ASL) from both normal and CF subjects. Because basal nucleotide levels may reflect the net activities of steady state cellular release and extracellular degradation, we characterized each of these processes. Membraneassociated nucleotide 5'-triphosphate (NTP) metabolism was measured in normal and CF nasal epithelial cells. Basal rates of ATP release were measured in well-differentiated normal and CF tracheobronchial cell cultures and in vivo during continuous nasal perfusion. The possibility of cAMP-dependent regulation of ATP release by isoproterenol was also tested in vivo.

\section{Materials and Methods}

Subjects

Normal (age $30.7 \pm 2.2$ years; range 21-44 years; $n=11$ ) and CF (age $22.5 \pm 1.1$ years; range $18-29$ years; $n=11$ ) subjects without visible nasal inflammation or recent nasal symptoms were studied after obtaining informed consent in accordance with the University of North Carolina Human Rights Committee. For the measurement of basal ATP concentration in nasal ASL, 11 normal and 11 CF subjects were studied. Basal UTP concentration was measured in five normal and five CF subjects. In vivo ATP release in response to isoproterenol and during continuous saline perfusion was studied in five normal and five CF subjects. Nasal submucosal gland secretions were obtained from four normal subjects and three subjects with CF. Normal and CF nasal and tracheobronchial cells for in vitro ATP release and metabolism experiments were harvested from surgical specimens, as described below.

\section{Materials}

$\left[{ }^{14} \mathrm{C}\right]$ glucose 1-phosphate and all nucleotides were obtained from Amersham Pharmacia (Piscataway, NJ). Tritium labeled ADP and UDP were prepared from their $\left[{ }^{3} \mathrm{H}\right]$ NTP precursor by incubating the appropriate substrate with hexokinase (Roche Molecular Biochemicals; Indianapolis, IN) and glucose (25 $\mathrm{mM})$ for $1 \mathrm{hr}$ at $37^{\circ} \mathrm{C}$, followed by heat inactivation of hexokinase by boiling for $2 \mathrm{~min}$. Complete conversion to the appropriate $\left[{ }^{3} \mathrm{H}\right] \mathrm{NDP}$ was confirmed using high performance liquid chromatography (HPLC). For nasal studies, methacholine was purchased from Amend Drug and Chemical (Irvington, NJ), and ipratropium bromide from Boehringer Ingelheim (Ridgefield, CT). All other reagents were purchased from Sigma (St. Louis, MO).

Measurement of Basal ATP and UTP Concentrations in Airway Surface Liquid in vivo

sample collection. A sampling device, consisting of a convex shield with a short sampling tube, was used to form a seal with the external nares without contacting the nasal mucosa. With this device, a $5 \mathrm{ml}$ volume of saline $\left(37^{\circ} \mathrm{C}\right)$ was gently instilled into the nasal cavity over several seconds and immediately recovered by gravity flow into a sterile container. A $1 \mathrm{ml}$ aliquot was immediately assayed for ATP concentration using the luciferinluciferase assay, and the remainder was frozen for subsequent measurements of UTP and urea concentrations. 
MEASUREMENT OF ATP CONCENTRATION VIA THE LUCIFERIN- LUCIFERASE ASSAY. Luminometry (AutoLumat 953; Berthold Analytical Instruments Inc., Nashua, NH) was performed on a $1 \mathrm{ml}$ aliquot of nasal lavage by injecting $100 \mu \mathrm{l}$ of freshly prepared luciferin-luciferase solution $\mathrm{N}$-2-hydroxyethyl piperazine-N-2-ethanesulfonic acid (HEPES) $25 \mathrm{mM}$; $\mathrm{MgCl}_{2} 6.25 \mathrm{mM}$; EDTA $0.63 \mathrm{mM}$; dithiothreitol $75 \mu \mathrm{M}$; bovine serum albumin (BSA) $1 \mathrm{mg} / \mathrm{ml}$; luciferase 5 $\mu \mathrm{g} / \mathrm{ml}$; luciferin $300 \mu \mathrm{M} ; \mathrm{pH} 7.8$ ) into the sample and measuring light production for $10 \mathrm{sec}$. An ATP standard curve was prepared in $1 \mathrm{ml}$ of $0.9 \% \mathrm{NaCl}$ for each group of sample measurements, and was linear over more than four orders of ATP concentration, from $1 \times 10^{-10}$ to $5 \times 10^{-6} \mathrm{M}$.

UTP CONCENTRATION ASSAY USING THE UDPGLUCOSE PYROPHOSPHORYLASE METHOD. Samples were boiled, then incubated for $60 \mathrm{~min}$ in $0.5 \mathrm{ml}$ Dulbecco's modified Eagle's medium (DMEM)/ HEPES pH 8.0 containing 0.5U/ml UDP-glucose pyrophosphorylase, $0.5 \mathrm{U} / \mathrm{ml}$ inorganic pyrophosphatase, and $1 \mu \mathrm{M}\left[{ }^{14} \mathrm{C}\right]$ glucose 1-phosphate $(0.15 \mu \mathrm{Ci})$. This coupled enzymatic reaction provided quantitative, linear conversion of UTP to $\left[{ }^{14} \mathrm{C}\right]$ UDP-glucose in the 1-300 nmol range $(30,31)$. Boiling the samples for $1 \mathrm{~min}$ terminated reactions. The percent conversion of $\left[{ }^{14} \mathrm{C}\right]$ glucose 1-phosphate to $\left[{ }^{14} \mathrm{C}\right]$ UDP-glucose was determined by HPLC and compared to a UTP standard curve.

HPLC ANALYSIS. Nucleotides were separated by HPLC via a Hypersil SAX column (Bodman, Aston, PA) using a two-solvent system consisting of buffers $\mathrm{A}\left(5 \mathrm{mM} \mathrm{NH} \mathrm{H}_{2} \mathrm{PO}_{4}, \mathrm{pH} 2.8\right)$ and B (375 mM NH $\mathrm{NH}_{2} \mathrm{PO}_{4}, \mathrm{pH}$ 3.7). A linear gradient was developed from $100 \%$ buffer A to $80 \%$ buffer B over the first $13 \mathrm{~min}$, followed by an additional $7 \mathrm{~min}$ of $100 \%$ buffer A. Absorbance at $264 \mathrm{~nm}$ was monitored with an SPD10A UV detector (Shimadzu, Columbia, MD), and radioactivity was measured online with a Flo-One detector (Packard; Meridan, CT).

UREA ASSAY. Measurement of urea concentration in nasal lavage samples was performed using the Sigma BUN (Endpoint) diagnostic kit, as described by the manufacturer. Because plasma urea measurements were not available for normal subjects, a normal value of $12 \mathrm{mg} / \mathrm{dl}$ was used for comparison in all cases. All CF subjects had recent clinical measurements of blood urea nitrogen (BUN), and none were outside of the normal range $(8-16 \mathrm{mg} / \mathrm{dl})$. The [urea]/12 quotient was used to normalize each basal ATP and UTP measurement for the extent of dilution (32).

LACTATE DEHYDROGENASE ASSAY. Nasal lavage samples obtained for measurement of basal ATP or UTP concentrations, as well as samples obtained during nasal perfusion, were assayed for lactate dehydrogenase activity using a colorimetric assay kit as directed by the manufacturer (Sigma).

\section{ATP Release from Cultured Airway Epithelial Cells}

CELL CULTURE. Well-differentiated human tracheobronchial and nasal epithelial cultures were produced from normal and CF specimens as previously described (33). Briefly, cells were harvested from surgical specimens (tracheobronchial or nasal turbinate) via protease digestion and grown on $100 \mathrm{~mm}$ tissue culture dishes in modified bronchiol epithelial growth media (BEGM) media (Biofluids Inc., Rockville, $\mathrm{MD})$. With the first passage, cells were seeded on Costar $12 \mathrm{~mm}$ Transwell-Col supports at a density of $0.25 \times 10^{6} / \mathrm{cm}^{2}$. Upon confluence, the apical surface was rinsed with phosphate-buffered saline (PBS) thrice weekly, and medium replaced only in the basolateral compartment. Cultures were used when they were fully differentiated, approximately 4 weeks after confluence.

ATP RELEASE ASSAY. To quantitate basal ATP release, CF and normal tracheobronchial epithelial cells were gently washed three times with PBS, then left undisturbed in an incubator $\left(37^{\circ} \mathrm{C} ; 5 \% \mathrm{CO}_{2}\right)$ for at least $3 \mathrm{hr}$ after adding $500 \mu \mathrm{l}$ minimal essential media (MEM) media to the apical surface. This incubation period was determined to be necessary to allow the ATP concentration in the apical bath to reach equilibrium. A trace amount of high specific activity $\left[{ }^{32} \mathrm{P}\right] \gamma$ ATP $(0.3 \mu \mathrm{Ci}: 3000 \mathrm{Ci} / \mathrm{mmole})$ then was added to the apical media, which was calculated to increase the ATP concentration in the media by $<0.15 \mathrm{nM}$. Samples were analyzed at various time-points with the luciferinluciferase assay to determine ATP concentration, and HPLC to quantitate the rate of $\left[{ }^{32} \mathrm{P}\right] \gamma$ ATP metabolism. Under equilibrium conditions (constant ATP concentration), the rate of ATP metabolism, as determined by the 
product of the initial rate of $\left[{ }^{32} \mathrm{P}\right] \gamma$ ATP hydrolysis and the steady-state ATP concentration, was assumed to equal the rate of ATP release. Cells originating from three normal and two CF patients were used in these experiments. Measurements from at least three cultures were made from each patient.

\section{ATP Release in vivo}

To test whether there was a basal rate of ATP release in vivo, a thin polyethylene catheter was placed under the inferior nasal turbinate using direct vision and carefully anchored to maintain stationary positioning. Perfusion with warmed $\left(37^{\circ} \mathrm{C}\right)$, isotonic saline was then initiated at $5 \mathrm{ml} / \mathrm{min}$, and the perfusate allowed to drip from the nose by gravity into a sterile container. Samples were collected at 1 minute intervals and immediately assayed for ATP concentration with the luciferin-luciferase assay. Addition of $15 \mathrm{nM}$ ATP to the superfusate resulted in quantitative recovery of the added ATP in the collected lavage fluid, suggesting little impact on ATP concentration by surface nucleotidases at this perfusion rate (data not shown).

To test whether increases in cellular cAMP induced ATP release in vivo, subjects were treated with ipratropium bromide (168 $\mu \mathrm{g}$ per nostril) 30-60 min prior to study to inhibit nasal submucosal gland secretion. $200 \mu \mathrm{l}$ of warmed $\left(37^{\circ} \mathrm{C}\right)$ isoproterenol $(10 \mu \mathrm{M})$ or vehicle $(0.9 \% \mathrm{NaCl})$ was applied to one nostril with a hand-held nebulizer, followed $2 \mathrm{~min}$ later by lavage with $5 \mathrm{ml}$ of warmed saline using the sampling technique described with basal ATP concentration measurements. The opposite nostril was treated in an identical fashion with the complementary agent (vehicle or isoproterenol). Samples obtained by this method were immediately frozen for subsequent analysis of ATP and urea concentrations.

\section{Regulation of ATP Concentration in ASL by Nasal Submucosal Gland Secretions in vivo}

COLLECTION OF NASAL SUBMUCOSAL GLAND SECRETIONS. To study the impact of submucosal gland (SMG) secretions on luminal ATP concentration, a baseline nasal lavage was first performed by delivering a total of $2 \mathrm{ml}$ of $0.9 \%$ saline to one nasal cavity with a hand-held nebulizer (100 $\mu \mathrm{l} /$ actuation). The lavage was recovered by expelling the liquid from the nose into a sterile specimen cup after every five actuations. Next, to obtain a lavage enriched with SMG secretions, methacholine $(30 \mathrm{mg}, 100 \mathrm{mg} / \mathrm{ml}$ solution) was delivered via nebulizer into the same nostril, followed 2 min later by a lavage as described above. To test the specificity of methacholine-induced effects, the opposite nostril was pretreated with ipratropium bromide (168 $\mu \mathrm{g}$, $42 \mu \mathrm{g}$ /actuation). 15 min later, methacholine (30 mg) was applied, followed in 2 min by a nasal lavage as described above. The volume of each lavage return was measured, mixed 1:1 with a Tris buffer solution [in $\mathrm{mM}$ : Tris $\mathrm{HCl}$, 100; $\mathrm{MgCl}_{2}, 2$; DL-Dithiothreitol (DTT), 3; $\mathrm{pH}$ 7.4], and incubated $\left(37^{\circ} \mathrm{C}\right.$ for $\left.30 \mathrm{~min}\right)$ with intermittent vortexing to aid dissolution of the mucinous secretions. The resulting solutions were centrifuged $(5 \mathrm{~min}, 600 \times \mathrm{g})$ to remove cells and particulate matter.

QUANTITATION OF TOTAL ADENINE NUCLEOTIDES IN NASAL LAVAGES. The initial ATP concentration in nasal lavages with and without methacholine treatment was measured using the luciferinluciferase assay, as described above. The total concentration of adenine nucleotides in lavages was then determined via enzymatic rephosphorylation of AMP and ADP to ATP, followed by the luciferin-luciferase assay, as previously described (34). Briefly, samples were boiled, mixed 1:1 with a reaction mixture containing pyruvate kinase $(22 \mathrm{U} / \mathrm{ml})$, adenylate kinase $(100 \mathrm{U} / \mathrm{ml})$, and phosphoenolpyruvate $(2.8 \mathrm{mM})$ in rephosphorylation buffer (in mM: Hepes, 25; $\mathrm{KOH}, 15 ; \mathrm{MgSO}_{4}, 10$ ) and incubated at room temperature for $3 \mathrm{hr}$. The resulting ATP concentration was determined with the luciferinluciferase assay, using ATP standard curves prepared in an identical reaction mixture.

ATP METABOLISM IN NASAL LAVAGES. Reactions were started by adding $\left[{ }^{3} \mathrm{H}\right] \mathrm{ATP}$ or $\left[{ }^{33} \mathrm{P}\right] \gamma \mathrm{ATP}$ (0.5 $\mu \mathrm{Ci}$ /sample; $1-500 \mu \mathrm{M}$ final concentration) to $0.1 \mathrm{ml}$ of lavage/buffer solution at $37^{\circ} \mathrm{C}$ and stopped with $0.5 \mathrm{ml}$ of cold $5 \%$ trichloroacetic acid (TCA). TCA was extracted from the samples using 8 volumes of ethyl ether. The metabolism of radiolabeled nucleotides was monitored using HPLC, as described above. The apparent $\mathrm{V}_{\text {max }}$ of ATP hydrolysis was determined using saturating substrate concentrations (0.5 mM), with reaction times chosen to ensure that $<15 \%$ metabolism of the added substrate had occurred. Comparisons were made between baseline 
lavages (no methacholine), lavages enriched with SMG secretions (post-methacholine), and lavages performed after ipratropium bromide + methacholine. The effect of selected ATPase inhibitors were tested, including $\mathrm{NaN}_{3}(20 \mathrm{mM})$, $\mathrm{HgCl}_{2}(10-100 \mu \mathrm{M})$, ouabain (1 mM), tetramisole $(5 \mathrm{mM})$, and sodium orthovanadate (ImM). The requirement for divalent cations was tested with EGTA (5.0 mM) and EDTA (5.0 mM). Inhibitors were added to lavage solutions $15 \mathrm{~min}$ prior to the addition of substrate.

\section{Metabolism of Nucleotide Triphosphates by Cultured Airway Epithelial Cells}

Nasal epithelial cell cultures were produced and maintained as described above. Cultures were rinsed three times with Krebs buffer $\left(\mathrm{KBR}\right.$, in $\mathrm{mM}: \mathrm{Na}^{+}, 140 ; \mathrm{Cl}^{-}, 120 ; \mathrm{K}^{+}, 5.2$; $\mathrm{HCO}_{3}^{-}, 25 ; \mathrm{HPO}_{4}^{-}, 2.4 ; \mathrm{Ca}^{2+}, 1.3 ; \mathrm{Mg}^{2+}, 1.3$; glucose, 5.2; HEPES 25, pH 7.4), then preincubated in bilateral KBR for $30 \mathrm{~min}\left(37^{\circ} \mathrm{C}\right.$, $5 \% \mathrm{CO}_{2} ; 350 \mu \mathrm{l}$ apical volume). Reactions were initiated with the addition of $\left[{ }^{3} \mathrm{H}\right]$ NTP $(1 \mathrm{mM}$, final concentration). At designated time points, a $30 \mu \mathrm{l}$ aliquot was sampled, added to $0.3 \mathrm{ml}$ ice-cold water, boiled, filtered, and analyzed by HPLC as described above. Time-points were chosen so that $<15 \%$ of the starting material had been metabolized.

A.

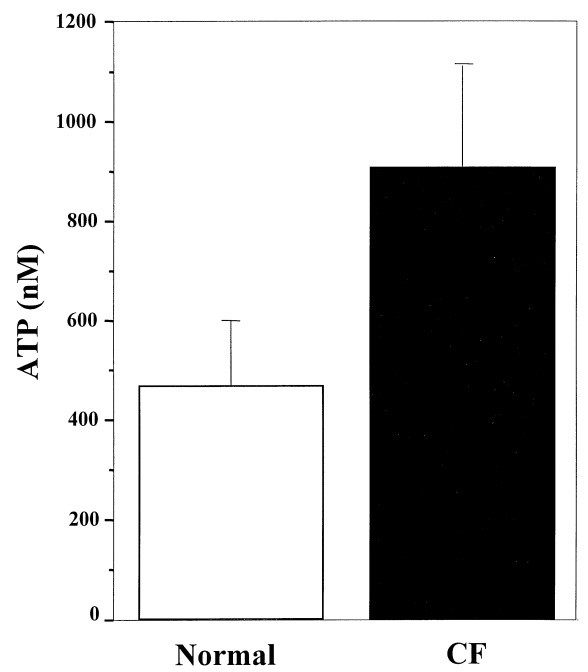

Fig. 1. Basal ATP and UTP concentrations in airway surface liquid from normal and cystic fibrosis (CF) subjects in vivo. (A) ATP concentrations were measured by the luciferin-luciferase assay ( $n=11$, normal and CF). (B) UTP concentrations were determined with an enzymatic assay and

\section{Statistics}

Unless otherwise stated, data are reported as mean \pm standard error (SE). Multiple samples obtained from the same subject were averaged so that the final results are expressed on a per subject basis. Comparisons were made with the Student's $t$-test, with $p<0.05$ considered significant.

\section{Results}

Basal Nucleotide Concentrations in Airway Surface Liquid in Vivo (Fig. 1)

The concentration of ATP in nasal ASL, after correcting for dilution using urea measurements, was $470 \pm 131 \mathrm{nM}$ in normal subjects, and $911 \pm 199 \mathrm{nM}$ in CF subjects. These values were not significantly different $(p=0.18)$. Similarly, no difference in UTP concentrations was detected in nasal ASL from normal and CF subjects $(37.0 \pm 7.2 \mathrm{nM}$ and $33.3 \pm 11.8 \mathrm{nM}$, respectively; $p=0.81 ;$ Fig. 1$)$. To test nucleotide stability in samples collected and stored by these methods, we performed pilot experiments that demonstrated the ATP concentration measured in a lavage aliquot was not different, whether assayed immediately after collection, after a brief centrifugation to pellet any cells

B.

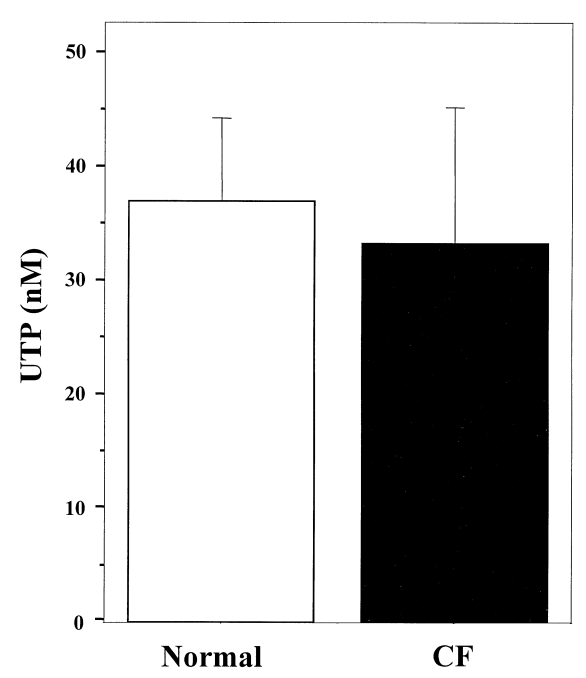

high performance liquid chromatography (HPLC; $n=5$, normal and CF). Nucleotide levels were corrected for dilution using parallel urea measurements. The mean nucleotide concentrations \pm standard error of the mean (SEM) are depicted. 
$(600 \times \mathrm{g}, 2 \mathrm{~min})$, or after a freeze-thaw cycle (variability $<5 \%$ for all samples; data not shown). To determine whether the presence of extracellular nucleotides was the result of cellular damage, we measured lactate dehydrogenase (LDH) activity in samples. LDH levels were uniformly below detectable levels by this method.

\section{Basal ATP Release from Cultured Nasal Epithelial} Cells: Normal vs. CF (Fig. 2)

The maintenance of a basal NTP concentration in vivo suggests that there may be a balance between constitutive NTP release and metabolism. To explore this possibility, we used cultured, polarized airway epithelia as a model of native airway epithelia. Although cultured airway cells have been shown in the past to respond to "non-injurious" mechanical stimuli by releasing ATP and UTP $(25,27,30)$, ATP release from non-stimulated airway epithelial

A.

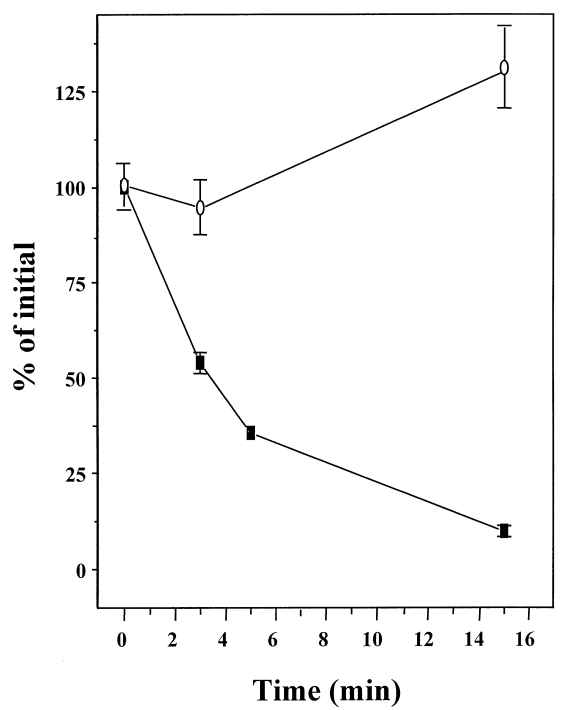

Fig. 2. Constitutive ATP release from cultured airway cells. (A) The basal ATP concentration and $\left[{ }^{32} \mathrm{P}\right] \gamma$ ATP mass measured in the mucosal bath of cultured cystic fibrosis (CF) tracheobronchial epithelial cells. Values represent the percent of initial values, obtained from three cultures from a CF patient. A trace quantity of $\left[{ }^{32} \mathrm{P}\right] \gamma \mathrm{ATP}$ was added to the apical media overlying welldifferentiated tracheobronchial cells that had been undisturbed for $3 \mathrm{hr}$. Sequential samples were analyzed for ATP concentration using the luciferinluciferase assay, and $\left[{ }^{32} \mathrm{P}\right] \gamma \mathrm{ATP}$ metabolism was cells has not been demonstrated previously. To test for constitutive release, we used a protocol that simultaneously measured the concentration of ATP in ASL and the rate of metabolism of $\left[{ }^{32} \mathrm{P}\right] \gamma \mathrm{ATP}$. A trace quantity of $\left[{ }^{32} \mathrm{P}\right] \gamma \mathrm{ATP}$ was introduced at time zero, and aliquots subsequently were withdrawn at designated intervals. The ATP concentration measured by the luciferin-luciferase assay in aliquots from the apical bath remained constant over time both in normal $(3.5 \pm 1.5 \mathrm{nM} ; n=3$ patients; 4 cultures/patient) and CF cultures (8.3 nM; $n=2$ patients; 4 cultures/patient). HPLC analysis of the same samples, however, detected the rapid hydrolysis of the terminal phosphate from $\left[{ }^{32} \mathrm{P}\right] \gamma \mathrm{ATP}$, indicating ongoing ATP metabolism (Fig. 2A). The observation of a constant ATP concentration, despite ongoing ATP hydrolysis, suggested that constitutive ATP release occurred under these basal conditions at a rate that precisely offset the measured basal hydrolytic rate. Importantly, the calculated rate of ATP release
B.

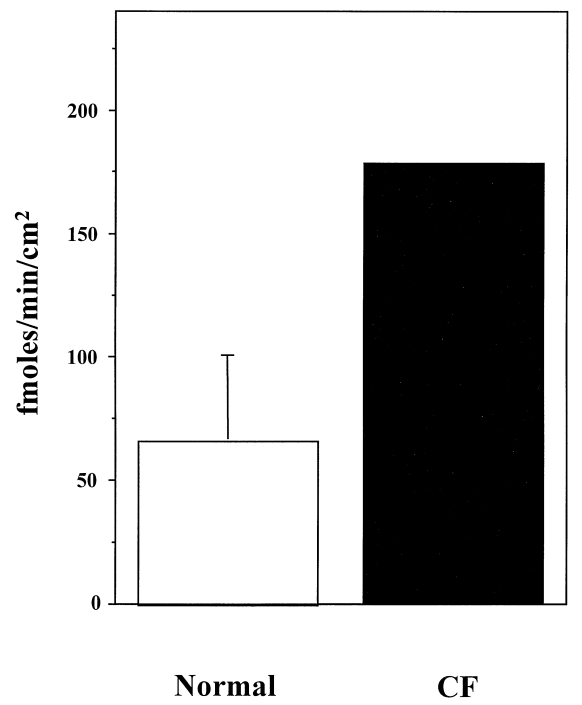

measured with high performance liquid chromatography (HPLC). ATP concentration (open circles) remained constant despite ongoing ATP metabolism, as shown by the breakdown of $\left[{ }^{32} \mathrm{P}\right] \gamma$ ATP (closed squares). The simultaneous measurement of ATP concentration and initial $\left[{ }^{32} \mathrm{P}\right] \gamma \mathrm{ATP}$ metabolic rate allowed calculation of the ATP release rate under these equilibrium conditions. (B) The mean calculated rate of constitutive ATP release ( \pm standard error of the mean; SEM) from normal (3 patients; $3-6$ cultures/patient) and CF (2 patients; 3-6 cultures/patient) airway cells. 
A.

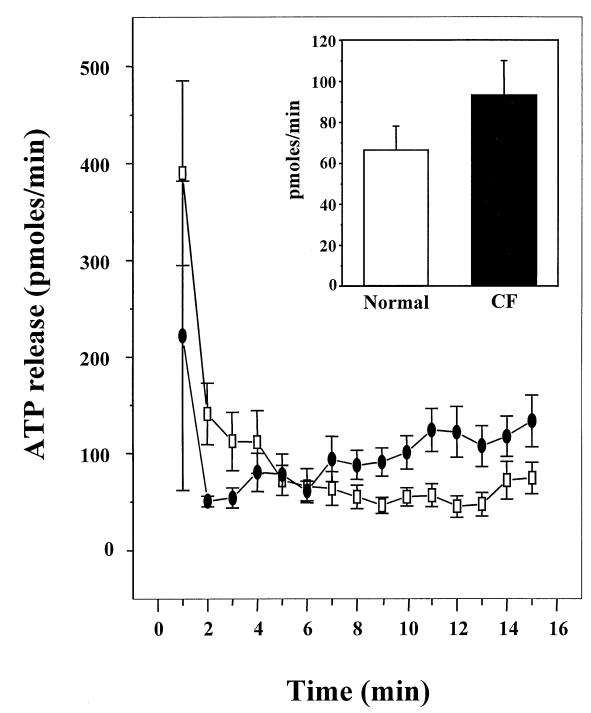

Fig. 3. In vivo ATP release under basal conditions and after isoproterenol treatment. (A) Basal ATP release during continuous saline perfusion $(5 \mathrm{ml} / \mathrm{min}$ ) was measured in vivo. Mean data ( \pm standard error of the mean; SEM) from normal (open squares; $n=5$ ) and cystic fibrosis (CF; solid circles; $n=5$ ) subjects is depicted. After an initial wash-down in ATP concentration, a stable level typically persisted for $\geqslant 15 \mathrm{~min}$. The inserted figure depicts the mean steady-state rate of ATP release from normal and CF nasal mucosae.

from normal $\left(66.6 \pm 34.2 \mathrm{fmoles} / \mathrm{min} \cdot \mathrm{cm}^{2}\right)$ and CF $\left(178.9 \mathrm{fmoles} / \mathrm{min} \cdot \mathrm{cm}^{2}\right)$ cells were not significantly different ( $p=0.21$; Fig. 2B).

\section{Basal ATP Release from Normal and CF Nasal Mucosa in vivo (Fig. 3A)}

To determine if normal and CF airways continuously released ATP in vivo, we used a protocol employing continuous nasal perfusion with warmed saline. Continuous perfusion resulted in a nearly constant concentration of ATP in the effluent within 2-3 min of initiating perfusion. This steady-state concentration was maintained for more than $15 \mathrm{~min}$ in most experiments, suggesting that ATP was released at a rate equal to its removal by perfusion under these conditions. Data from normal $(N=5)$ and CF $(N=5)$ subjects revealed no difference in the mean steady-state rate of ATP release (from minutes 3 to 15) during saline perfusion $(66.7 \pm 11.6$ vs. $93.5 \pm 16.6$ pmoles $/ \mathrm{min}$, respectively; $p=0.26$; Fig. $3 \mathrm{~A}$ ). LDH was below detectable levels in these samples.
B.

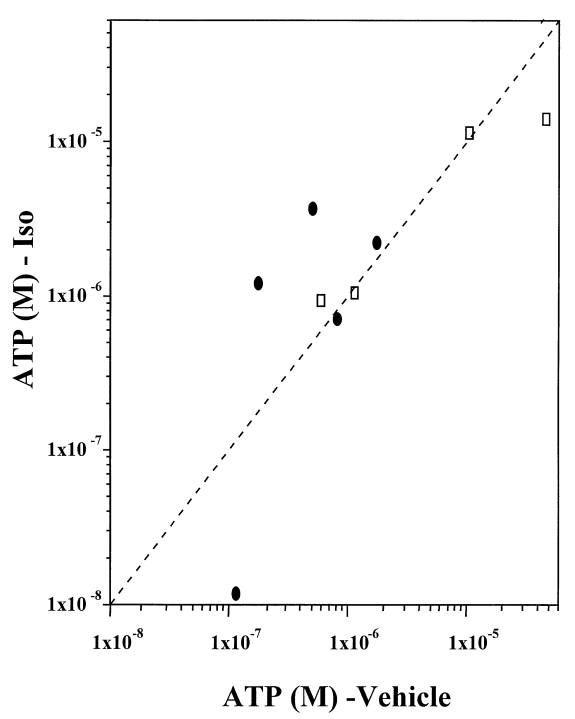

(B) Comparison of isoproterenol vs. vehicle on ATP release. Using a hand-held nebulizer, isoproterenol $(10 \mu \mathrm{M})$ was applied to one nostril in normal ( $n=5$; solid circles) and CF ( $n=4$; open squares) subjects, and an equal volume of vehicle $(.9 \% \mathrm{NaCl})$ to the opposite nostril. Nasal lavages were performed 2 min after applying the respective agents, and ATP and urea concentrations were measured. The ATP concentration after isoproterenol vs. vehicle (corrected for dilution) from each patient is plotted with respect to the line of unity (dashed line).

Regulated Release of ATP from the Superficial Epithelium in vivo (Fig. 3B)

We tested whether an agent that activates CFTR chloride conductance by raising intracellular cAMP also stimulated ATP release in vivo in normal or CF subjects. Isoproterenol $(10 \mu \mathrm{M})$ was delivered onto the nasal mucosa with a hand-held nebulizer, followed by ASL sampling as performed during basal [NTP] measurements. The contralateral nostril was used for a vehicle control. The ATP concentration measured in these lavages was corrected for dilution using urea concentration measurements. In these experiments, we did not observe an increased ATP concentration in lavages after isoproterenol treatment compared with vehicle controls in either normal or CF subjects (Fig. 3B).

\section{Effect of Submucosal Gland Secretions on NTP Concentrations in ASL (Fig. 4)}

Because glands secrete the liquid lining nasal surfaces, we hypothesized that submucosal gland (SMG) secretions may act in series with 
A.

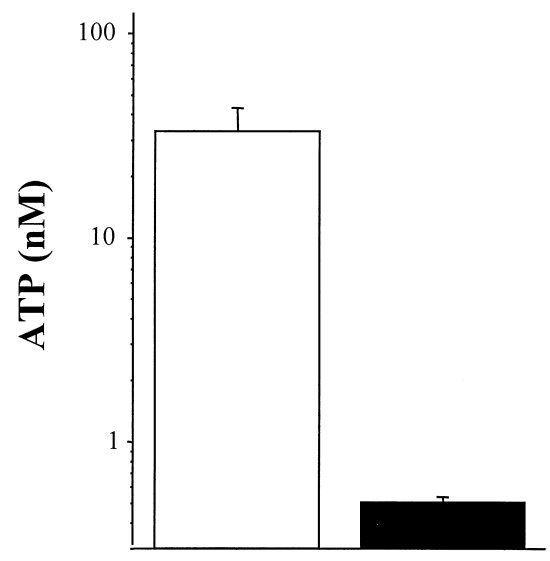

Baseline Methacholine

C.

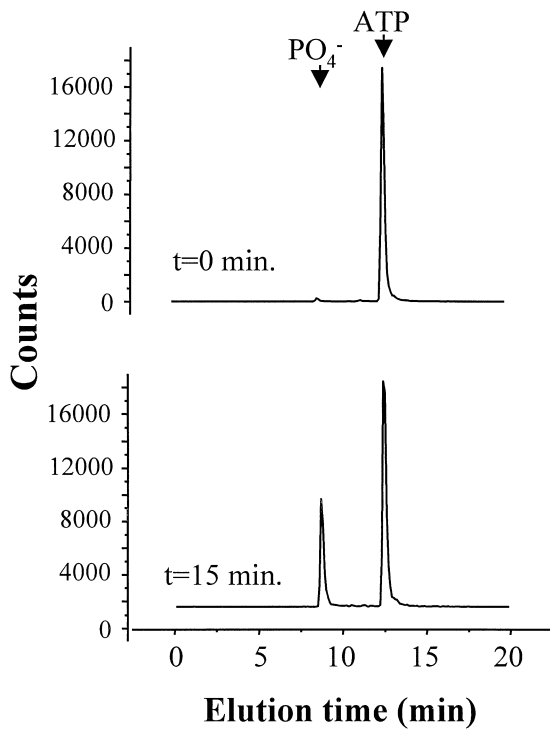

Fig. 4. The effect of nasal submucosal gland secretions on ATP concentration. (A) The ATP concentration measured in nasal lavages (not corrected for dilution) collected after stimulating submucosal gland (SMG) secretion with methacholine was reduced dramatically (closed column), relative to basal lavages (open column). (B) Exogenous ATP (1000 nM) added to nasal lavages rapidly disappeared only in those obtained after stimulating submucosal gland secretion (squares), compared with baseline lavages

the surface epithelia to regulate ASL ATP levels in large airways. Two mechanisms predict that SMG secretions would contain a large concentration of nucleotides. First, as ATP is packaged and released from granules in nerve $(35,36)$ and adrenal chromaffin cells (37), SMGs may also release ATP via an exocytotic mechanism. Second,
B.

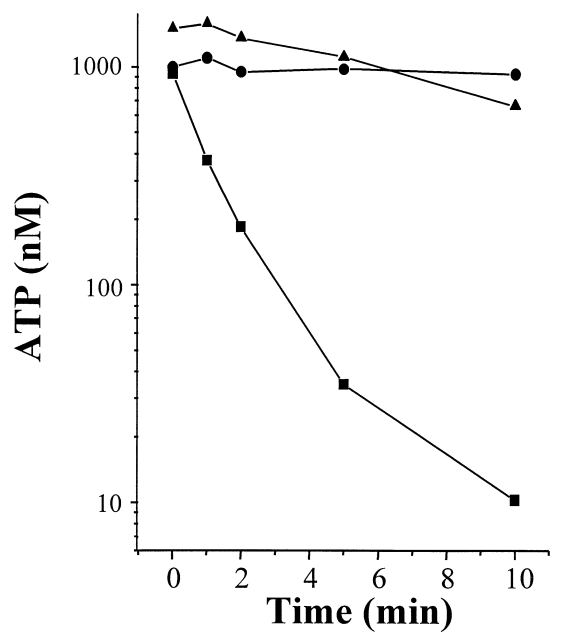

D.

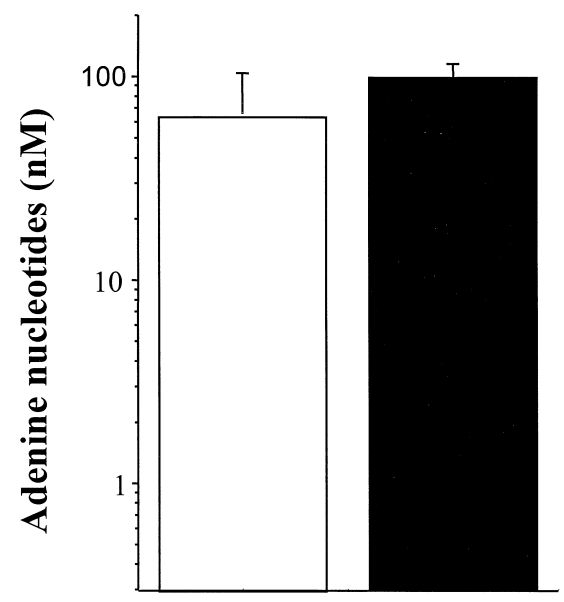

\section{Baseline Methacholine}

(triangles). Boiling the secretion-rich lavage abolished this enzyme activity (circles). (C) High performance liquid chromatography (HPLC) chromatogram demonstrating hydrolysis of the terminal phosphate group from $\left[{ }^{33} \mathrm{P}\right] \gamma$ ATP $(100 \mu \mathrm{M})$ in a nasal lavage enriched with SMG secretions. (D) The total concentration of adenine nucleotides present in lavages before (open column) and after (closed column) SMG stimulation was determined by rephosphorylating all AMP and ADP in the sample to ATP, followed by the luciferin-luciferase assay.

since CFTR is most abundantly expressed in SMGs (38), CFTR-mediated nucleotide release might be most readily detected in nasal lavages from normal, as compared with CF, subjects after stimulating SMG secretion. We tested these hypotheses by stimulating SMG secretion in vivo with a cholinergic agonist, followed by 
the luciferin-luciferase assay to measure the ATP concentration.

In contrast to our hypotheses, the ATP concentration in lavages after stimulating gland secretion was markedly lower than in basal lavages from normal (Fig. 4A) and CF subjects. This difference could not be attributed to simple dilution of ASL nucleotides by gland secretions, as the volume of gland secretions accounted for only $10-15 \%$ of the final lavage volume. Instead, this marked decrease in ATP concentration reflected the presence of a secreted NTPase, as evidenced by the observation that exogenous ATP rapidly disappeared when added to nasal lavages enriched with gland secretions (Fig. 4B). Boiling lavages for $1 \mathrm{~min}$ prevented the metabolism of exogenously added ATP (Fig. 4B). HPLC experiments using $\left[{ }^{33}\right.$ P $]$ YATP and $\left[{ }^{33} \mathrm{P}\right] \gamma \mathrm{UTP}$ as substrates demonstrated that the conversion of NTP to NDP occurred via cleavage of the terminal phosphate group (Fig. 4C), thus confirming the presence of a NTPase.

Selected ATPase and phosphatase inhibitors were tested to characterize the type of NTPase activity present in SMG secretions. Ouabain (1 mM), sodium orthovanadate (1 mM), and tetramisole $(5 \mathrm{mM})$ had no effect on the observed ATPase activity. $\mathrm{HgCl}_{2}$, which was reported to potently inhibit apyrase (CD39, ATP dihydrophosphorylase), had no inhibitory effect at concentrations up to $100 \mu \mathrm{M}$ (39). Sodium azide $(20 \mathrm{mM})$, an inhibitor of both F-type (mitochondrial) and E-type ATPases, produced a $37 \pm 2.5 \%$ inhibition of enzyme activity. Chelation of magnesium and calcium resulted in a $90 \pm 3.5 \%$ loss of enzyme activity. This panel of results was similar to that reported for E-type ATPases (40).

The secretion of a soluble NTPase caused decreased ATP levels in lavages after SMG stimulation and complicated testing the hypothesis that release of ATP could occur from SMGs. To assess ATP secretion in the presence of a NTPase, we quantitatively rephosphorylated all AMP and ADP in these nasal lavages to ATP, using myokinase and pyruvate kinase, and then measured the final concentration of ATP with the luciferin-luciferase assay. These experiments demonstrated that the total amount of adenine nucleotides in lavages from normal subjects before and after cholinergic stimulation was not different (Fig. 4D). These findings, therefore, suggested that SMGs were not a source of extracellular adenine nucleotides.

\section{Nucleotide Triphosphate Metabolism by a Soluble NTPase (Fig. 5)}

Because of the surprising finding that SMGs secreted a soluble NTPase, we investigated its

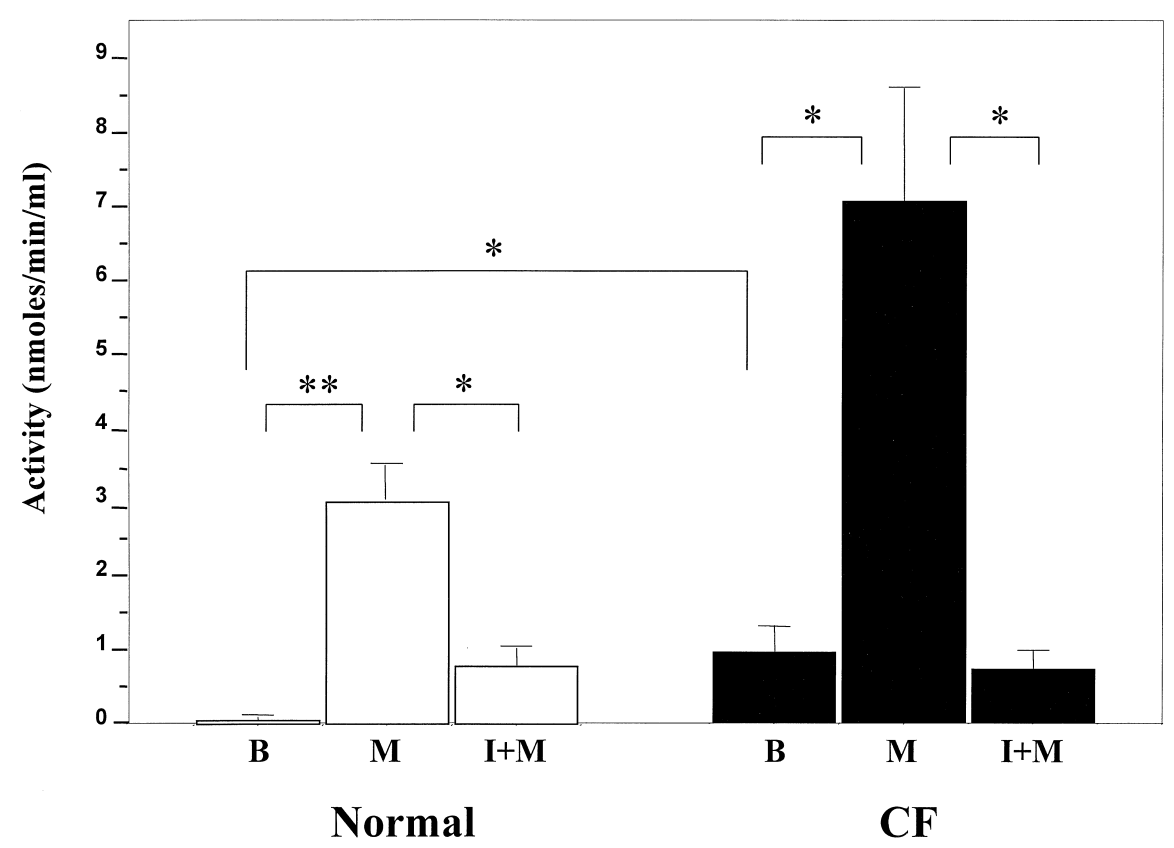

Fig. 5. ATPase activity in nasal lavages. ATPase activity in baseline lavages (B), after methacholine treatment $(\mathrm{M})$, and after ipratropium bromide followed by methacholine $(\mathrm{I}+\mathrm{M})$ from normal $(n=4)$ and cystic fibrosis $(\mathrm{CF} ; n=3)$ patients. For comparisons, * denotes $p<0.05$, and ${ }^{* *}$ denotes $p<0.005$. 
activity on the nasal surface of normal and CF subjects under both basal conditions and after submucosal gland stimulation (Fig. 5). Prior to SMG stimulation, lavages from normal subjects contained a small, but detectable, amount of ATPase activity; whereas, basal lavages from CF subjects had significantly more activity $(0.07 \pm 0.03$ vs. $0.97 \pm 0.34$ nmoles/ min.ml, respectively; $p<0.05)$. After stimulating SMG secretion with methacholine, a markedly increased ATPase activity was observed both in normal (3.02 \pm 0.46 nmoles/ $\mathrm{min} \cdot \mathrm{ml})$ and CF $(7.07 \pm 1.50 \mathrm{nmoles} / \mathrm{min} \cdot \mathrm{ml})$ subjects (Fig. 5). Pretreatment with the cholinergic receptor antagonist ipratropium bromide nearly abolished the observed increase in ATPase activity in response to methacholine (Fig. 5), demonstrating that the methacholine induced effect was indeed a cholinergic receptor mediated event and not a non-specific/ toxic reaction to the drug.

\section{Nucleotide Triphosphate Metabolism by Airway Epithelial Cultures}

To test for nucleotide metabolism on normal and CF airway superficial epithelial surfaces, we measured the initial rates of ATP and UTP metabolism on well-differentiated, cultured nasal epithelial cells. CF epithelia demonstrated a moderately increased apparent $\mathrm{V}_{\max }$ for ATP hydrolysis $(4.41 \pm 0.32$ vs. $3.62 \pm 0$. $30 \mathrm{nmoles} / \mathrm{min} \cdot \mathrm{cm}^{2} ; n=5$ patients; $p<.005$ ) and UTP hydrolysis $(5.81 \pm 0.49$ vs. $4.28 \pm$ $0.41 \mathrm{nmoles} / \mathrm{min} \cdot \mathrm{cm}^{2} ; n=4$ patients; $p<$ $0.005)$ relative to normal nasal epithelial cells.

\section{Discussion}

An important issue in the field of extracellular nucleotide biology is whether $\mathrm{ABC}$ transporters regulate the release of ATP. This issue bears directly on the pathophysiology of CF, because of earlier reports, emanating primarily from in vitro cell culture models, describing a role for CFTR in epithelial cell ATP release. However, subsequent reports addressing the role of CFTR in epithelial ATP release are remarkable for their lack of consensus. Based on their disparate findings, groups have concluded that CFTR itself functions as an ATP channel $(7,9,13,41)$, is a regulator of a separate but associated channel $(10,11)$, or has no relationship to ATP transport whatsoever (25-29). Although there has been much speculation over the fac- tors leading to these differences (41-43), controversy in this field continues to exist. We, therefore, turned to a human in vivo system in an attempt to ascertain the physiologic importance of CFTR-mediated ATP release.

Using a lavage technique designed to minimize mechanical perturbation of the nasal epithelium, we measured basal levels of ATP in nasal ASL from normal and CF subjects in vivo. No significant difference in ATP concentrations was found between normal and CF subjects under these conditions (Fig. 1). We extended these studies to UTP, because of its potency at airway $\mathrm{P}_{2} \mathrm{Y}_{2}$ receptors and reports that UTP was released by airway epithelia (30). Once again, no difference in UTP concentrations between CF and normal subjects was detected in vivo.

Although a normal and CF basal nucleotide levels were similar within a given experimental system, a large discrepancy appeared to exist between the resting levels of ATP in the media bathing cultured epithelia (Fig. 2) and our ureacorrected in vivo measurements (Fig. 1). To more directly compare data from these different experimental systems, we normalized the mass of recovered ATP to the epithelial surface area that was sampled. In the case of the in vivo experimental system, the volume of ASL recovered was calculated by applying simple dilution principles to the concentration of urea measured in these samples. The epithelial surface area associated with this ASL volume then was determined by assuming that the nasal ASL height approximated $50 \mu \mathrm{M}$ [based on published figures for total nasal ASL volume (32) and surface area (44)]. Using this approach, the mean basal levels of ATP in ASL were $2.36 \times 10^{-12}$ and $4.27 \times 10^{-12} \mathrm{moles} / \mathrm{cm}^{2}$ in normal and CF subjects, respectively. These data are in remarkably close agreement with the mean resting ATP levels measured in vitro, where $1.6 \times 10^{-12}$ and $3.8 \times 10^{-12} \mathrm{moles} / \mathrm{cm}^{2}$ were measured in normal and CF cultures, respectively. The consistency of these results suggest that our in vitro cultures are indeed a good model for the study of airway nucleotide release, and lessen the likelihood that our in vivo results are spurious. Although this high degree of correlation is reassuring, one must keep in mind that several assumptions are incorporated into these calculations, including the height of the nasal ASL layer in vivo. Perhaps more importantly, we do not know whether the concentration or number of moles bathing a cultured epithelium might change as the vol- 
ume of overlying media is reduced from the "thick-film" conditions imposed by these experiments $(\sim 4000 \mu \mathrm{M})$, to more physiologic "thin-film" conditions (ASL 10-50 $\mu \mathrm{M}$ in height).

Although these data suggest that reduced basal nucleotide concentrations do not contribute to CF airways disease pathogenesis, they do not definitively rule out the hypothesis that CFTR is involved in ATP transport, because reduced nucleotide release by CF epithelia could have been offset by reduced metabolism by ecto-nucleotidases. We, therefore, directly measured rates of ATP release and extracellular metabolism by normal and CF airway epithelial cultures. Using a novel assay to measure basal rates of ATP release under truly non-stimulated conditions, we found no difference in the rates of ATP release by normal and CF cultures (Fig. 2). Similarly, rates of nucleotide metabolism by CF airway cultures were not reduced, but in fact modestly, though significantly, elevated, compared with normal cultures. Together, these data support the notion that the important pathways for nucleotide release from cells are intact in the CF epithelium. In addition, this assay is the first to demonstrate that ATP release occurs continuously during non-stimulated conditions and, thus, provides a mechanism for the maintenance of ATP levels in ASL in the presence of active ecto-nucleotidases.

The two prior reports of basal ATP release from normal and CF epithelia differ in their findings. These results (Fig. 2) are consistent with those of Grygorczyk et al., who did not detect differences in resting ATP concentrations, nor mechanically stimulated ATP release, between normal and CF epithelial cell lines (27). Our results differ from Taylor et al. (14), who detected significant basal ATP release from normal but not CF cell lines. There are differences in the bioluminescent assays used to detect ATP release that may contribute to these discrepant results. The assay we developed avoids mechanically stimulated ATP release (e.g. washing cells, changing media, or movement of the culture plate) and is the first to incorporate measurements of endogenous nucleotide metabolism, thus, allowing determination of ATP release rates without limitation by concomitant ectonucleotidase activity. Perhaps more importantly, our study is the first to directly compare normal and CF primary cultured cells, rather than immortalized cell lines.
Although our in vitro studies allowed us to examine nucleotide release and metabolism under non-stimulated conditions, the lack of suitable reagents precluded direct measurement of metabolism in vivo. Measurements of ATP release, however, were feasible. Slow, continuous perfusion of the nasal epithelium with warmed saline was associated with a rapid reduction of the ATP concentration in the superfusate over the first 2-3 min, followed by steady-state levels. The initial peak in ATP levels may reflect washout of ATP preexistent on the mucosal surface, and/or mechanically stimulated ATP release resulting from catheter placement and the initiation of perfusion. Because perfusion served to reduce the effects of extracellular metabolism, the lower steadystate levels reflected the rate of ATP release. Like the measurements made in vitro, the ATP release rates measured in normal and $\mathrm{CF}$ subjects were not different (Fig. 3A). Cell lysis as the source of the measured ATP seems unlikely, because cell damage, in response to slow saline perfusion, would need to occur at a constant rate to produce the observed constant ATP concentration during $15 \mathrm{~min}$ of perfusion.

Two approaches were employed to test whether regulated release of ATP occurred in vivo and if it was dependent on CFTR function. First, we explored the regulation of ASL ATP concentration by $\beta$-adrenergic receptor agonists. No increase in ATP levels was detected in vivo in normal subjects (or CF) in response to isoproterenol, suggesting that cAMP was not able to stimulate ATP release from the superficial epithelium via CFTR activation (Fig 3B). Second, because CFTR is most abundantly expressed in glandular epithelia (38), we tested the hypothesis that normal glands, when stimulated, would vigorously secrete ATP; whereas, CF glands might be expected to exhibit defective ATP secretion. These experiments detected no significant release of ATP from submucosal glands in either group and, instead, revealed the secretion of a soluble NTPase from both normal and CF glands. Together, these experiments support the notion that CFTR-mediated ATP release is not biologically relevant in airways.

In addition to addressing the hypothesis that CFTR regulates ATP release, our data have implications for the physiology of the $\mathrm{P}_{2} \mathrm{Y}_{2}$ receptor system in airways in vivo. Our data provide the first in vivo measurements of nucleotide concentrations in ASL. The measured basal ATP concentration of $\sim 0.5-1.0 \mu \mathrm{M}$ approximates the 
concentration at which chloride secretion can first be detected in vivo using the nasal potential difference technique (45). Relatively small increases in ATP release, therefore, might lead to a rapid increase in chloride secretion and, perhaps, accelerate mucociliary clearance rates. This basal ATP concentration would also be unlikely to cause receptor desensitization, as has been shown to occur experimentally at higher nucleotide concentrations in heterologous cells (46). The much lower concentration of UTP in ASL (Fig. 1) suggests that ATP is the more physiologically important $\mathrm{P}_{2} \mathrm{Y}_{2}$ agonist in vivo.

The finding that glands secrete a NTPase also adds to our understanding of nucleotide receptor regulation in airways. Although the paradigm for extracellular nucleotide metabolism generally has been limited to cell-attached ecto-nucleotidases, growing precedent exists for secreted nucleotidases. Relevant to our findings are reports of secreted ATPase and ATP-diphosphohydrolases (ATPDase) activities from other glandular tissues such as oviduct $(47,48)$ and prostate $(49)$. In these tissues, an ATPDase may be secreted into the luminal compartment via microvesicular shedding from the plasma membrane (50). Our finding of cholinergic receptor-mediated ATPase secretion from SMGs suggests that the rate of glandular secretion in vivo provides a means of regulating nucleotide concentrations on airway surfaces. Whether gland hypersecretion in diseases such as CF and chronic bronchitis reduces lower airway ATP concentration, with a potential consequence being reduced mucociliary clearance rates, will be important to study.

In summary, our data show that: (1) the basal concentrations of ATP and UTP in nasal ASL in vivo are not reduced in CF; (2) rates of ATP release from CF epithelia are not reduced either in vitro or in vivo; and, (3) cAMP does not regulate ATP release. These findings suggest that CFTR-mediated nucleotide release does not play an important role in determining the extracellular NTP concentrations in vivo or a pathophysiologic role in the development of CF lung disease. Our data do indicate that ATP is present in the ASL of normal and CF subjects at concentrations well-suited for the dynamic regulation of mucociliary clearance via $\mathrm{P}_{2} \mathrm{Y}_{2}$ receptors.

\section{Acknowledgments}

This work was supported by the Cystic Fibrosis Foundation (CFF L543).

\section{References}

1. Anderson MP, Gregory RJ, Thompson S, et al. (1991) Demonstration that CFTR is a chloride channel by alteration of its anion selectivity. Science 253: 202-205.

2. Bear CE, Li CH, Kartner N, et al. (1992) Purification and functional reconstitution of the cystic fibrosis transmembrane conductance regulator (CFTR). Cell 68: 809-818.

3. Stutts MJ, Canessa CM, Olsen JC, et al. (1995) CFTR as a CAMP-dependent regulator of sodium channels [see comments]. Science 269: 847-850.

4. Stutts MJ, Rossier BC, Boucher RC. (1997) Cystic fibrosis transmembrane conductance regulator inverts protein kinase A-mediated regulation of epithelial sodium channel single channel kinetics. J. Biol. Chem. 272: 14037-14040.

5. Boucher RC. (1994) Human airway ion transport. Part one. Am. J. Respir. Crit Care Med. 150: 271- 281.

6. Boucher RC. (1994) Human airway ion transport. Part two. Am. J. Respir. Crit Care Med. 150: 581-593.

7. Reisin IL, Prat AG, Abraham EH, et al. (1994) The cystic fibrosis transmembrane conductance regulator is a dual ATP and chloride channel. $J$. Biol. Chem. 269: 20584-20591.

8. Schwiebert EM, Egan ME, Hwang TH, et al. (1995) CFTR regulates outwardly rectifying chloride channels through an autocrine mechanism involving ATP. Cell 81: 1063-1073.

9. Prat AG, Reisin IL, Ausiello DA, Cantiello HF. (1996) Cellular ATP release by the cystic fibrosis transmembrane conductance regulator. Am. J. Physiol. 270: C538-C545.

10. Sugita M, Yue Y, Foskett JK. (1998) CFTR Cl- channel and CFTR-associated ATP channel: distinct pores regulated by common gates. $E M B O$ J. 17: 898-908.

11. Jiang Q, Mak D, Devidas S, et al. (1998) Cystic fibrosis transmembrane conductance regulatorassociated ATP release is controlled by a chloride sensor. J. Cell Biol. 143: 645-657.

12. Sprague RS, Ellsworth ML, Stephenson AH, Kleinhenz ME, Lonigro AJ. (1998) Deformationinduced ATP release from red blood cells requires CFTR activity. Am. J. Physiol. 275: H1726-H1732.

13. Cantiello HF, Jackson GR, Grosman CF, et al. (1998) Electrodiffusional ATP movement through the cystic fibrosis transmembrane conductance regulator. Am. J. Physiol. 274: C799-C809.

14. Taylor AL, Kudlow BA, Marrs KL, Gruenert DC, Guggino WB, Schwiebert EM. (1998) Bioluminescence detection of ATP release mechanisms in epithelia. Am. J. Physiol. 275: C1391-C1406.

15. Bennett WD, Olivier KN, Zeman KL, Hohneker KW, Boucher RC, Knowles MR. (1996) Effect of uridine 5'-triphosphate plus amiloride on mucociliary clearance in adult cystic fibrosis. Am. J. Respir. Crit. Care Med. 153: 1796-1801. 
16. Olivier KN, Bennett WD, Hohneker KW, et al. (1996) Acute safety and effects on mucociliary clearance of aerosolized uridine $5^{\prime}$-triphosphate $+/-$ amiloride in normal human adults. Am. $J$. Respir. Crit. Care Med. 154: 217-223.

17. Evans JH, Sanderson MJ. (1999) Intracellular calcium oscillations regulate ciliary beat frequency of airway epithelial cells. Cell Calcium 26: 103-110.

18. Korngreen A, Priel Z. (1996) Purinergic stimulation of rabbit ciliated airway epithelia: control by multiple calcium sources. J. Physiol. (Lond) 497 (Pt 1): 53-66.

19. Uzlaner N, Priel Z. (1999) Interplay between the NO pathway and elevated $[\mathrm{Ca} 2+] \mathrm{i}$ enhances ciliary activity in rabbit trachea. J. Physiol. (Lond) 516 (Pt 1): 179-190.

20. Knowles MR, Clarke LL, Boucher RC. (1991) Activation by extracellular nucleotides of chloride secretion in the airway epithelia of patients with cystic fibrosis [see comments]. N. Engl. J. Med. 325: 533-538.

21. Stutts MJ, Fitz JG, Paradiso AM, Boucher RC. (1994) Multiple modes of regulation of airway epithelial chloride secretion by extracellular ATP. Am. J. Physiol. 267: C1442-C1451.

22. Lethem MI, Dowell ML, Van Scott M. (1993). Nucleotide regulation of goblet cells in human airway epithelial explants: normal exocytosis in cystic fibrosis. Am. J. Respir. Cell Mol. Biol. 9: 315322 .

23. Abdullah LH, Davis SW, Burch L, et al. (1996) $\mathrm{P} 2 \mathrm{u}$ purinoceptor regulation of mucin secretion in SPOCl cells, a goblet Cell line from the airways. Biochem. J. 316 (Pt 3): 943-951.

24. Abraham EH, Prat AG, Gerweck L, et al. (1993) The multidrug resistance $(\mathrm{mdr} 1)$ gene product functions as an ATP channel. Proc. Natl. Acad. Sci. USA 90: 312-316.

25. Watt WC, Lazarowski ER, Boucher RC. (1998) Cystic fibrosis transmembrane regulatorindependent release of ATP. Its implications for the regulation of $\mathrm{P} 2 \mathrm{Y} 2$ receptors in airway epithelia. J. Biol. Chem. 273: 14053-14058.

26. Reddy MM, Quinton PM, Haws C, et al. (1996) Failure of the cystic fibrosis transmembrane conductance regulator to conduct ATP. Science 271: 1876-1879.

27. Grygorczyk R, Hanrahan JW. (1997) CFTRindependent ATP release from epithelial cells triggered by mechanical stimuli. Am. J. Physiol 272: C1058-C1066.

28. Grygorczyk R, Tabcharani JA, Hanrahan JW. (1996) CFTR channels expressed in CHO cells do not have detectable ATP conductance. $J$. Membr. Biol. 151: 139-148.

29. Li C, Ramjeesingh M, Bear CE. (1996) Purified cystic fibrosis transmembrane conductance regulator (CFTR) does not function as an ATP channel. J. Biol. Chem. 271: 11623-11626.
30. Lazarowski ER, Harden TK. (1999) Quantitation of extracellular UTP using a sensitive enzymatic assay. Br. J. Pharmacol. 127: 1272-1278.

31. Lazarowski ER, Homolya L, Boucher RC, Harden TK. (1997) Direct demonstration of mechanically induced release of cellular UTP and its implication for uridine nucleotide receptor activation. J. Biol. Chem. 272: 24348-24354.

32. Kaulbach HC, White MV, Igarashi Y, Hahn BK, Kaliner MA. (1993) Estimation of nasal epithelial lining fluid using urea as a marker. J. Allergy Clin. Immunol. 92: 457-465.

33. Matsui H, Randell SH, Peretti SW, Davis CW, Boucher RC. (1998) Coordinated clearance of periciliary liquid and mucus from airway surfaces. J. Clin. Invest. 102: 1125-1131.

34. Hampp R. (1985) Luminometric method. In Bergmeyer J, Grossl M (eds.) Metabolites 2: Tri- and Dicarboxylic Acid, Purines, Pyrimidines and Derivatives, Coenzymes, Inorganic Compounds. VCH Publishers, Deerfield Beach, FL, pp. 370-379.

35. Burnstock G, Cocks T, Kasakov L, Wong HK. (1978) Direct evidence for ATP release from non-adrenergic, non-cholinergic ("purinergic") nerves in the guinea-pig taenia coli and bladder. Eur. J. Pharmacol. 49: 145-149.

36. Kasakov L, Ellis J, Kirkpatrick K, Milner P, Burnstock G. (1988) Direct evidence for concomitant release of noradrenaline, adenosine 5 '-triphosphate and neuropeptide Y from sympathetic nerve supplying the guinea-pig vas deferens. J. Auton. Nerv. Syst. 22: 75-82.

37. Hollins B, Ikeda SR. (1997) Heterologous expression of a $\mathrm{P} 2 \mathrm{x}$-purinoceptor in rat chromaffin cells detects vesicular ATP release. J. Neurophysiol. 78: 3069-3076.

38. Engelhardt JF, Yankaskas JR, Ernst SA, et al. (1992) Submucosal glands are the predominant site of CFTR expression in the human bronchus. Nat. Genet. 2: 240-248.

39. Picher M, Cote YP, Beliveau R, Potier M, Beaudoin AR. (1993) Demonstration of a novel type of ATP-diphosphohydrolase (EC 3.6.1.5) in the bovine lung. J. Biol. Chem. 268: 4699-4703.

40. Plesner L. (1995) Ecto-ATPases: identities and functions. Int. Rev. Cytol. 158: 141-214.

41. Abraham EH, Okunieff P, Scala S, et al. (1997) Cystic fibrosis transmembrane conductance regulator and adenosine triphosphate [letter]. Science 275: 1324-1326.

42. Schwiebert EM. (1999) ABC transporter-facilitated ATP conductive transport. Am. J. Physiol. 276: C1-C8.

43. Devidas S, Guggino WB. (1997) The cystic fibrosis transmembrane conductance regulator and ATP. Curr. Opin. Cell Biol. 9: 547-552.

44. Cole P. (1982) Upper respiratory airflow. In: Proctor DF, Andersen I (eds.) The Nose: Upper Airway Physiology and the Atmospheric Environment. Elsevier Biomedical Press B.V., Amsterdam, pp. 163-189. 
45. Knowles MR, Clarke LL, Boucher RC. (1992) Extracellular ATP and UTP induce chloride secretion in nasal epithelia of cystic fibrosis patients and normal subjects in vivo. Chest 101: 60S-63S.

46. Clarke LL, Harline MC, Otero MA, et al. (1999) Desensitization of $\mathrm{P} 2 \mathrm{Y} 2$ receptor-activated transepithelial anion secretion. Am. J. Physiol. 276: C777-C787.

47. Strobel RS, Nagy AK, Knowles AF, Buegel J, Rosenberg MD. (1996) Chicken oviductal ectoATP-diphosphohydrolase. Purification and characterization. J. Biol. Chem. 271: 16323-16331.
48. Nagy AK, Knowles AF, Nagami GT. (1998) Molecular cloning of the chicken oviduct ectoATP-diphosphohydrolase. J. Biol. Chem. 273: 16043-16049.

49. Ronquist G, Brody I. (1985) The prostasome: its secretion and function in man. Biochim. Biophy. Acta 822: 203-218.

50. Beaudoin AR, Vachereau A, Grondin G, St Jean P, Rosenberg MD, Strobel R. (1986) Microvesicular secretion, a mode of Cell secretion associated with the presence of an ATPdiphosphohydrolase. FEBS Lett. 203: 1-2. 